\title{
A Cloud Based Electronic Office Framework for Ethiopian Public Universities (CBEOFEPU)
}

\author{
Gizatie Desalegn $^{1,}$, , Mesfin Abebe ${ }^{2}$, Fisha Haileslassie ${ }^{1}$, Melese Kalayu ${ }^{3}$ \\ ${ }^{1}$ Department of Computer Science, Faculty of Technology, Debre Tabor University, Debre Tabor, Ethiopia \\ ${ }^{2}$ Department of Computing, Adama Science and Technology University, Adama, Ethiopia \\ ${ }^{3}$ Department of Information Technology, Raya University, Maichew, Ethiopia
}

\section{Email address:}

gizatied2004@gmail.com (G. Desalegn)

${ }^{*}$ Corresponding author

\section{To cite this article:}

Gizatie Desalegn, Mesfin Abebe, Fisha Haileslassie, Melese Kalayu. A Cloud Based Electronic Office Framework for Ethiopian Public Universities (CBEOFEPU). International Journal on Data Science and Technology. Vol. 6, No. 1, 2020, pp. 1-9. doi: $10.11648 /$ j.ijdst.20200601.11

Received: December 11, 2019; Accepted: December 23, 2019; Published: January 6, 2020

\begin{abstract}
An effective cloud-based electronic office management system plays a crucial role in delivering services in a better way. The main goal of this research is to create a smart environment, a digital workplace solution, good communication, and collaboration between employers and Ethiopian higher education institutions and to add some cloud computing capabilities to the electronic office. The proposed system is intended to better drive the effective development of Smart society and to advance a step into an era of the paperless, replace the previous manual handling of documents with an efficient electronic system. The study uses questionnaire, Interview, and observation data collection techniques and the developed prototype and proposed framework evaluate by different users, experts in software engineering and related fields. This study proposes a private cloud platform architecture for electronic office in Ethiopian public universities Software as a Service. The CloudBased Electronic Office Framework (CBEOF) adapts the IBM Cloud Reference Architecture (IBMCRA), the NIST Cloud Reference Architecture, and the Microsoft Web Application Architecture to take advantage of all the considerations and capabilities of a cloud-based software architecture.
\end{abstract}

Keywords: Cloud Computing, Cloud-based Architecture, Electronic Office, Software Architecture, Dynamic Form Builder, Digital Workplace Solution

\section{Introduction}

In the area of government, Information and Communication Technologies (ICT) applications are encouraging to improve the delivery of services to citizens. Moreover, ICT play an increasingly important role in people's daily lives, revolutionize work and change business rules [1]. By applying information technology in government system, Electronic Government (e-government) can be created.

The paperless and transparent E-office system is designed to effectively connect the various departments and management offices, by taking into account the needs of employees and customers. Moreover, it's cloud-based, delivering all of the resources, application software, processing power, data storage, backup facilities, and development tools as a set of services over the Internet, allowing employers, customers, to use applications without installing them on their computers, and also providing access to save files from any computer with an internet connection [2].

Using web services and cloud computing technologies, the entire electronic office was stored in one place in the cloud and made available to authorized users from everywhere through extensive access to the network.

The main objective of the study is to design a framework of cloud-based E-Office system for Ethiopian public universities and to develop a prototype.

Over the past twenty years, the use of ICT has radically changed the practices and procedures of almost all forms of corporate business and governance. In previous study, there 
are many problems related to office tasks like physically moving files and documents takes a long time and requires continuous supervision from desk to desk before senior officials make the final decision. As a result, many important decisions are delayed due to the slow movement of the files and / or the lack of availability in the office to eliminate these files [3].

Rastogi, Dr. Ashish [4], The study proposed a model-based approach for the implementation of cloud computing frameworks in e-government, to reflect the way in which the government functions in terms of the government, its relationship with its citizens, institutions, companies and the cooperation with other governments and the discussion. It reflects how to overcome the problem of e-government in developing countries.

It also discusses how to transform traditional governance into electronic governance based on the cloud and how users can easily use electronic documents and improve government services in education, health care and social empowerment. The critical issue discussed for developing countries is the infrastructure needed to implement electronic services. Use of cloud computing for better electronic governance in developing countries and proposal of a framework based on models to implement cloud computing.

G. Sahoo, K. Mukherjee [5], the proposed study was Cloud Computing Future Framework and Intelligent Computer Web Service by E-Governance. Adequate use of resources that are scarce day by day. Superior technology compared to the traditional architecture of server-based electronic governance. The main problem is that government services cannot easily obtain citizens. The purpose of the document was, therefore, to design the intelligent computational service model and the proposed cloud computing framework for electronic government. Address electronic government services for all categories of users, from rural citizens to citizens of the city. The researcher used the Hadoop model. In addition, it is the central part to communicate to users, access the different web services of electronic government with a laptop or sophisticated desktop, the thin client's / cell phones are unreachable for a large number of users in a country like India.

\section{Materials and Methods}

\subsection{Research Methodology}

The Cloud-based e-governance and E-office frameworks were studied to propose the highly secured and scalable cloud-based E-office framework for Ethiopian public universities to transform the current manual and semicomputerized documentation to highly sophisticated electronic offices at Ethiopian public universities.

We started the study by conducting interview and questionnaire with University Higher Managerial Office, Faculty Deans, Administrative and Academic Departments, Research Dean, ICT Professionals, and Teachers in Ethiopian public universities to collect data about the current information on the process of office task specifically on how to send/receive, manage and routing of different documents and letters, different services form based request, and approval/rejecting processing, collaboration and messaging among different employers of the institution and related to institutional knowledgebase repository.

Based on these steps, a design of cloud-based E-office framework and its prototype were developed to address the problem in (Figure 1).

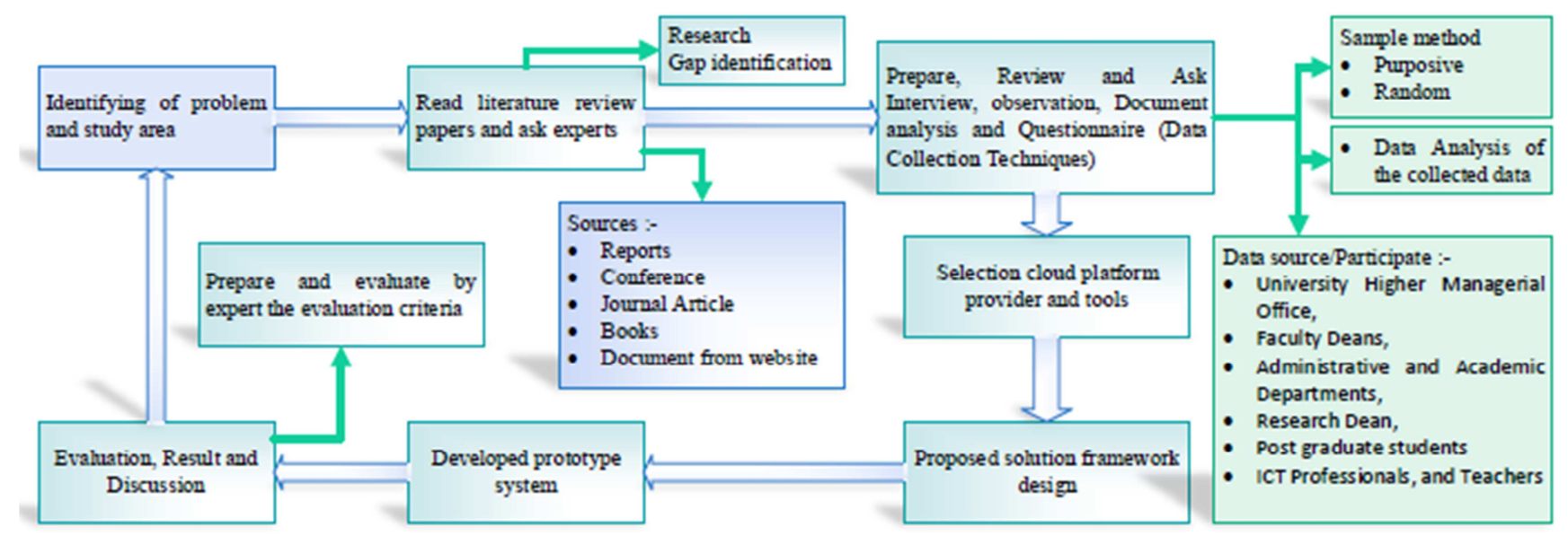

Figure 1. Research Methodology.

\subsection{Research Design}

For any research studies, there are four commonly used approaches, which are quantitative, qualitative, design oriented and mixed method [6]. The quantitative research approach uses standardized measures, numerical values, have large sample size, and analyze data using statistical program. It is applicable to phenomena that can be expressed in terms of quantity or number [7]. On the other hand, qualitative research approach is focused on describing situations, phenomenon, problem, or event; tends to be more in-depth and have smaller sample size [8]. A mixed methods research design is a procedure to analyze, collect, and mix research and quantitative and qualitative methods in a single study to understand a research problem [9]. 
Design-Oriented Research creates an artifact by artificial object and its basic objective is producing new knowledge during this process. It is mostly focus on knowledge flows and process steps that is problem awareness, suggestion, development, evaluation, and conclusion; eventually aims to get result or output [10].

In this study, a combination of qualitative and designoriented research method was used for data manipulation and to evaluate the functionality of the prototype. To demonstrate the usefulness of the proposed E-office framework for Ethiopian public universities and their employers, the designoriented research methodology was used in this study.
Design-oriented research method is a problem-solving model [11].

As shown from Table 1, from question number 1-5 Higher Managerial officers, Directors and Deans selected randomly and question number 6-8 selected based on purposive sampling. Stratified sampling calculator used to determine the sampling size from total population [12]. Higher managerial office $=1 \%$, Administrative Units $=1 \%$, School Deans $=0.5 \%$, Academic Department Heads $=1.5 \%$, Research Deans $=0.5 \%$, ICT Professionals $=4.1 \%$, Teachers $=41 \%$, and Post Graduate Students $=5.6 \%$.

Table 1. Sampling Population Size.

\begin{tabular}{|c|c|c|c|c|c|}
\hline No & Sample Population & $\begin{array}{l}\text { Total No. Departments / } \\
\text { Population }\end{array}$ & $\begin{array}{l}\text { Distributed } \\
\text { Questionnaire } \\
\end{array}$ & $\begin{array}{l}\text { Returned } \\
\text { Questionnaire } \\
\end{array}$ & Returned in (\%) \\
\hline 1 & Higher managerial officers and supporting department & 6 & 2 & 2 & 100 \\
\hline 2 & Administrative Units & 10 & 4 & 3 & 75 \\
\hline 3 & School/Faculty Deans & 5 & 1 & 1 & 100 \\
\hline 4 & Academic Department Heads & 15 & 4 & 4 & 100 \\
\hline 5 & Research Dean & 5 & 1 & 1 & 100 \\
\hline 6 & ICT professionals & 40 & 10 & 9 & 90 \\
\hline 7 & Teachers & 400 & 18 & 15 & 83.3 \\
\hline \multirow[t]{2}{*}{8} & Post Graduate Students & 55 & 15 & 12 & 80 \\
\hline & Total & 536 & 55 & 47 & 91 \\
\hline
\end{tabular}

As we have seen from the above Table 1 the response rate from the respondent around $91 \%$. Therefore, there is unreturned questionnaire from different respondents.

\subsection{Data Collection Techniques}

Research differs in a number of ways, but they have some similarities. One of the common aspects is the need to collect data. The interviewed experts came from ICT professionals, Computing and Electrical Engineering staff. This allows us to correctly capture the required data and simplify the process of data collection.

This data collection task involves three phases:

(1) In depth interviews interviewed a total of seven Ethiopian Public Universities (EPUs) staff members, two of ICT professionals, two of the academic and administrative departments, three of teachers on their office task ideas, their indispensability, efficiency and effectiveness, $\log$ file and status of the transaction, current situations, barriers and solutions to provide it continuously. About cloud computing include in the interview questions.

(2) The questionnaire addressed a number of issues related to Ethiopian public universities office tasks for different employers and postgraduate students.

(3) Observation tasks in observed based on workplace study on EPU office tasks in different offices like in Computer Science Engineering Department, Registrar, Academic Vice President, and ICT office for 4 days. In addition, we are part of a higher education institution and we observe the customer satisfaction on current manual system as a way to manage and process of various documents, current communication systems between departments, faculty and senior officials and the repetitive form based inquiry, its efficiency, and effectiveness of the current system, technology adaptation and the knowledgebase. This is done through different techniques, but getting the right information was extremely difficult, as observed.

Using the questionnaire, we examined the work efficiency and effectiveness of the current manual system, the type of delivery services, the problems they face with the current system, and the possible solutions to the current problem and employer's interest. It would be Electronic office in Cloudbased implemented. As well as their use of ICT and other technologies in their activities specifically related to the office task. Then we have added questions to interest them when the office task is cloud-based and is supported by current technologies to handle various requests, and communication between Department, Faculty, and senior officers using various communication tools such as Emessaging, E-forum to conduct discussion.

\subsection{Data Analysis}

Questionnaire and interview are a structured technique used to collect primary data to decide how to collect replies, questionnaire design, and analyze data after identifying the population and sample [13-14]. The techniques are focused on the importance of creating a smart office environment for the Ethiopian public universities community, the efficiency, and effectiveness of the current manual system and how to forward the paper documents, currently how they are deployed, and what efforts have been made to make it available to you one after another. In addition, how the institution handles a variety of request, form-based tasks related to technology, collaboration, and knowledgebase environment. 
To know how many the university employers and post distributed 55 and 47 returned from respondents. graduate students responded. The total number of in the

Table 2. Response rate of the questionnaire.

\begin{tabular}{|c|c|c|c|c|}
\hline No & Questionnaire List & Yes & No & No, in $(\%)$ \\
\hline 1 & Efficiency of the current communication system. & 2 & 45 & 95.7 \\
\hline 2 & The losing rate of different documents and letters. & 47 & 0 & 100 \\
\hline 3 & Is the paperless office system working place create smart environment? & 47 & 0 & 100 \\
\hline 4 & Is there any log file that can hold the transaction history on your side to know the status of delivery for your request? & 1 & 46 & 97.8 \\
\hline 5 & Does the current system support an easy way to search or find documents and letters? & 1 & 46 & 97.8 \\
\hline 6 & $\begin{array}{l}\text { Is there any automated office management system in your university to route or send/receive documents and to } \\
\text { process form-based request? }\end{array}$ & 2 & 45 & 95.7 \\
\hline 7 & $\begin{array}{l}\text { Do you believe to improve your effectiveness and efficiency, if E-office management system is implemented in your } \\
\text { university? }\end{array}$ & 46 & 1 & 97.8 \\
\hline 8 & Is there any central repository of institutional knowledge base and best practices? & 3 & 44 & 93.6 \\
\hline 9 & In average, is there any delay of the current manual system in movement of file level and to give decision-making? & 47 & 0 & 100 \\
\hline 10 & Can you say the current manual system is following a standard workflow the given task? & 2 & 45 & 95.7 \\
\hline 11 & Is there any way to report/complain if a task is delayed or does not performed in time? & 3 & 44 & 93.6 \\
\hline
\end{tabular}

The Ethiopian public universities community found rough understanding and the situation regarding the current manual system, its needs, and the associated problems. As they explained, to manage the various documents from one office level to another office, widely distributed by e-mail, him/herself, colleague / friend, telephone, and personal messenger. In almost all cases, paper documents are used for requesting decisions from the other media of their supervisor, such as telephone and e-mail, to require decisions based on the sensitivity of the decision. The use of e-mail for official communication is minimal, only $4.3 \%$ believe that the current communication system is efficient in their university.

The problems of the current communication system have also become ineffective, time consuming, and expensive, with security issues, delaying communication in the case of a personal messenger, and some people may not be interested or need to read emails, various tasks that are not perform on time, high paper used and it has the unavailability or absence of senior executives. In addition, most respondents are interested in an intelligent environment or a paperless workplace by automating the workflow / business process and implementing online communication such as Emessaging.

In general, the current manual system for analyzing data, they believe around $97.8 \%$, the current manual handling is not an easy way to search documents, there is no log file containing the transaction history, and there is difficulty to know the status of the delivery request.

And the respondents believe that around 97.8\%, if the Eoffice system implement improves the efficiency and effectiveness of office work such as: effective storage and accessibility, efficient document tracking features, it can easily manage, share and disseminate various documents with colleagues from a centrally stored repository, improve the delivery of files, reduce delays, and have good communication between employers from one level to another.

\section{Selection of Cloud Provider and Design of Conceptual Framework for EPU}

\subsection{Selection of Cloud Provider}

The study contains a selection of tools to design the proposed framework and to implement its prototype for the purpose of concept verification and evaluation purposes.

The main criteria for choosing Microsoft Azure are;

Firstly, it provides the developer with more deployment options than the other three platforms and more sets of application programming interfaces (APIs).

Secondly, is that we are familiar with Microsoft products such as the Microsoft's Visual Studio (VS) Integrated Development Environment (IDE), Angular JS, and SQL storage. Therefore, for most popular cloud service providers uses Microsoft Azure.

Third, the upcoming releases of Azure are going to support applications written in languages such as Python and PHP.

Fourth, it resembles existing Windows environment a lot. In general, the migrating applications to cloud is easy. This partially stems from the fact that Azure's services exploited by an application whether it run locally or in the cloud. The developer can deploy locally using web deployments on IIS.

In addition, Microsoft has features like:

1. High availability (99.9\%) of the application and the data.

2. Open and flexible cloud platform that enables to rapid creation, deployment, and management of applications in a global network of Microsoft managed datacenters.

3. Possible to integrate public, private cloud applications with the existing IT environment and quick deployment of the application to new customers etc.

In order to design this framework for the provision of the software as a service, we have added ideas or concepts from IBM CCRA [13], NIST Cloud Reference Architecture [14], 
Microsoft Web Application Architecture [15-17], and cloud-based systems. available literatures on software architecture approaches for

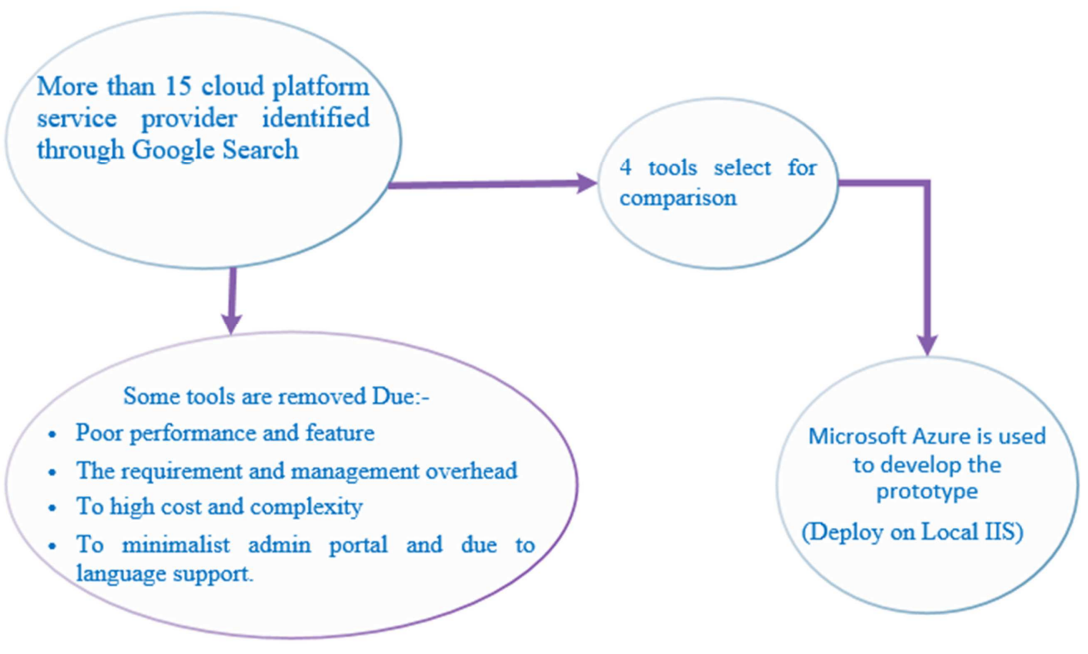

Figure 2. Conceptual Framework of CBEOF for EPU.

\subsection{The Conceptual Framework of Cloud Based Electronic Office for EPU}

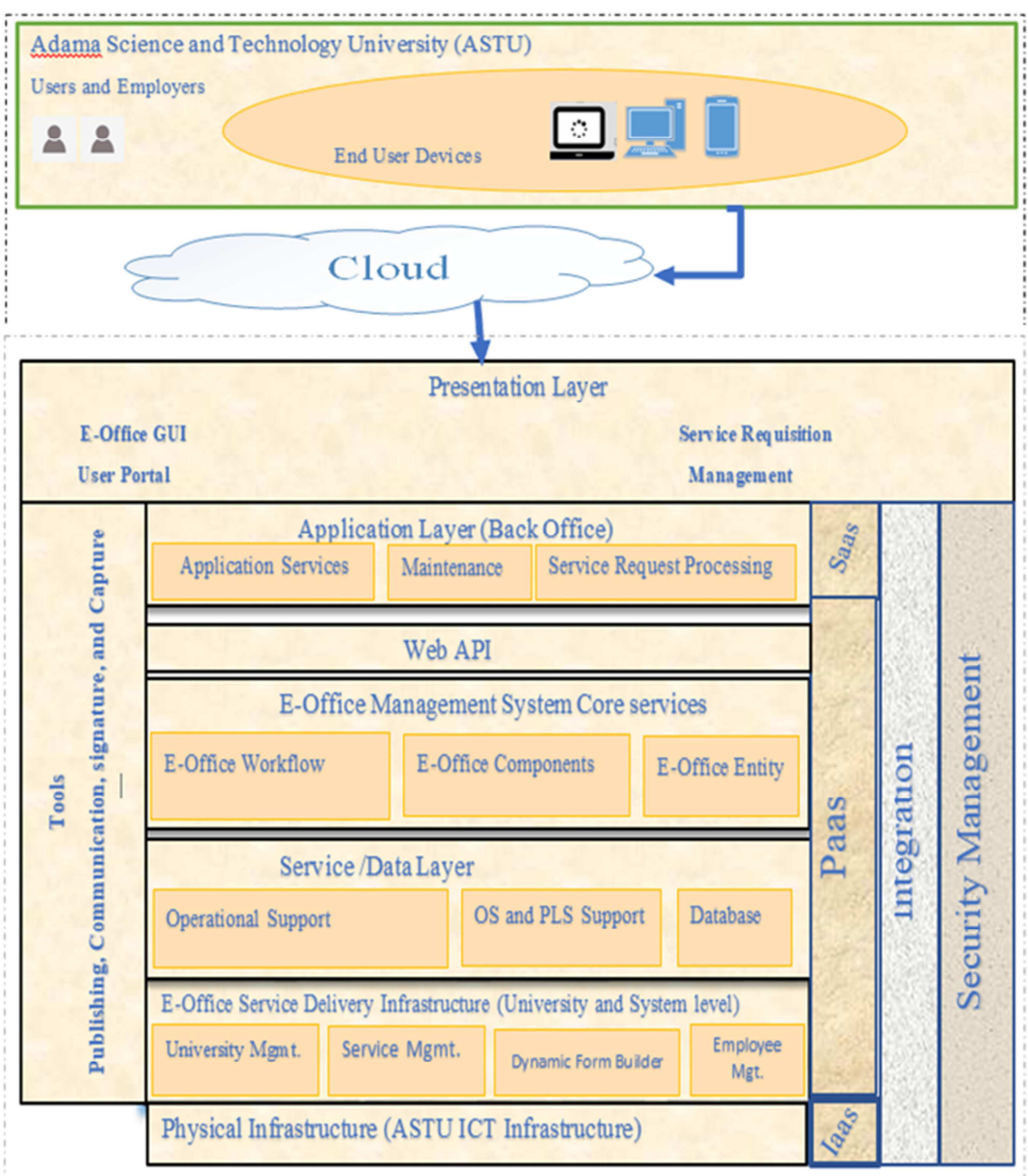

Figure 3. Conceptual Framework of CBEOF for EPU.

Figure 3 is own work; it consists of four layers managing the E-office components and the infrastructure for the provision of services. In the CBEOF, users / employers can request E-office services from the cloud provider. The details 
of the CBEOF layers are described below.

\subsection{Conceptual System Architecture of CBEOF}

The system architecture shows that the relationship among service requisition with request processing via internet.
Before that the service delivery infrastructure must be prepared in order to perform the service requisition and service processing. The data analysis used as input for Eoffice components in the figure 4 below.

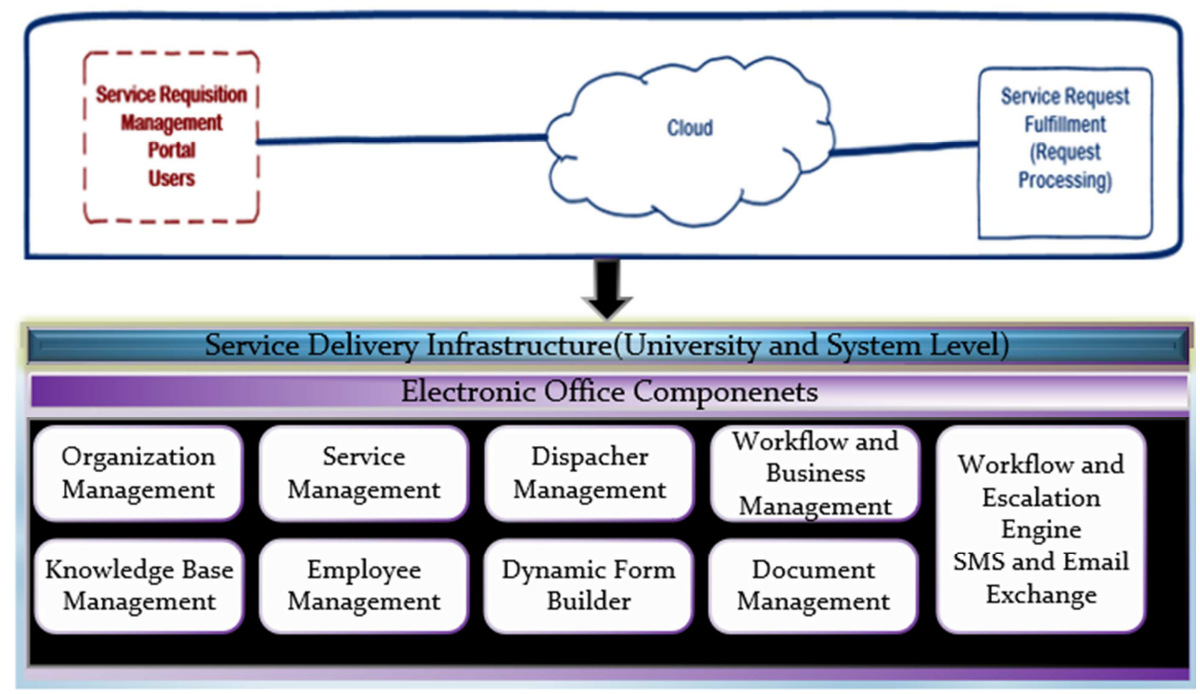

Figure 4. Conceptual System Architecture of CBEOF for EPU.

\section{Evaluation, Result and Discussion of the Study}

\subsection{Evaluation}

In this section, we review surveys that we conducted with users, IT professionals, and software development experts to evaluate and discuss the prototype system being developed and discuss the current manual system. The current practice of processing Ethiopian public universities office tasks is through a manual method of sending / receiving, approving / rejecting, and forwarding various documents from one office level to another office level, sharing the institutional knowledgebase, communication between employers and various offices, manual preparation of various institutional forms such as annual leave, teachers load, file request, and material purchase request. Later, these office tasks will not run electronically.

In addition, there are many problems with the current manual method, such as: delays in moving documents from one office level to another office, non-standard workflows and services form, i.e. inconsistency with office work procedures, iteration and duplication of work and summary preparation, lack of system approach, too many manual approvals, and reviews, time spent on non-core tasks, lack of coordination / communication between departments, schools, and senior administrative offices, delays in decision-making due to time spent in retrieving facts and information, lack of security and confidentiality of documents, lack of information officers / staff, and poor knowledge management could be avoided.

Reflect on the previous problems, we have proposed a platform framework based on the cloud (Software as a Service) and implemented a prototype system that creates a common alliance through the use of manual method to electronic office work, then bringing institutional and individual efficiency through faster decision-making, error free output, collaborative workspaces, communication speed, optimal resource utilization, scalability, and movement effectiveness through output / result orientation, quality of output, on-time delivery, and cost effectiveness (value for money) through accessibility and availability of information and through commitment. Transparency is created to provide employees with user-friendly operation, a trusted digital environment, easy file retrieval, remote capabilities, and online help / assistance.

Compared to the manual method, it follows the standard workflow and services form, the dynamic creation of forms, logging of transaction history, interactive and supported by current technologies and tools, but does not mean that it replaces the entire manual office task, but as a bridge for software developers.

ICT professionals from Ethiopian public universities, colleagues, and experts in software engineering, related fields evaluated the design of the technical system give their comments and suggestions on the CBEOF system developed. They recommend that the system more users friendly and easier to use to be more effective. Therefore, the comments were positive, and these comments and recommendations were left to the respective Ethiopian public universities to the professionals who perform their functions, and the development of the full implementation will be easy for the software engineers.

Finally, this architecture and framework for sharing different institutional forms, simple communication between employers, and various office has been found through the 
implementation of messaging, and forum discussions, sending / receiving, approval / rejection, and routing of various documents, and building of an exchange institutional knowledge is effective and important if it is fully implemented with the comments of all interested stakeholders.

1. To validate this evaluation was done on how users use the CBEOF user interface and attractive interface. They practiced/used the designed user interface and other features of the developed prototype. Finally, they suggest several additional problems to be included in the system. Therefore, the evaluation questions were made with four EPU employers from different offices, three ICT professionals working in the EPU, three experts and eight colleagues in software engineering and related fields.

2. To evaluate the CBEOF system, each user group uses its own pages created for them. Moreover, rate the result in terms of usability of the prototype and framework of the CBEOF system in the cloud.

3. The framework and developed prototype evaluate and re-work the framework and modify the prototype.

Here is the evaluation result prepared from the prototypedeveloped system and framework of the CBEOF system. It represents Poor (1), Fair (2), Good (3), V. Good (4), Excellent (5).

Table 3. Evaluation criteria for developed prototype system and framework of the CBEOF.

\begin{tabular}{|c|c|c|c|c|c|c|}
\hline No & Evaluation Criteria & 1 & 2 & 3 & 4 & 5 \\
\hline 1 & How do you rank your satisfaction with the developed prototype system? & - & 2 & 10 & 5 & 1 \\
\hline 2 & How do you rank the dynamic form builder to design for different services? & - & - & 9 & 7 & 2 \\
\hline 3 & How is the browser's response time when you start requesting services on the server? & - & 1 & 9 & 8 & - \\
\hline
\end{tabular}

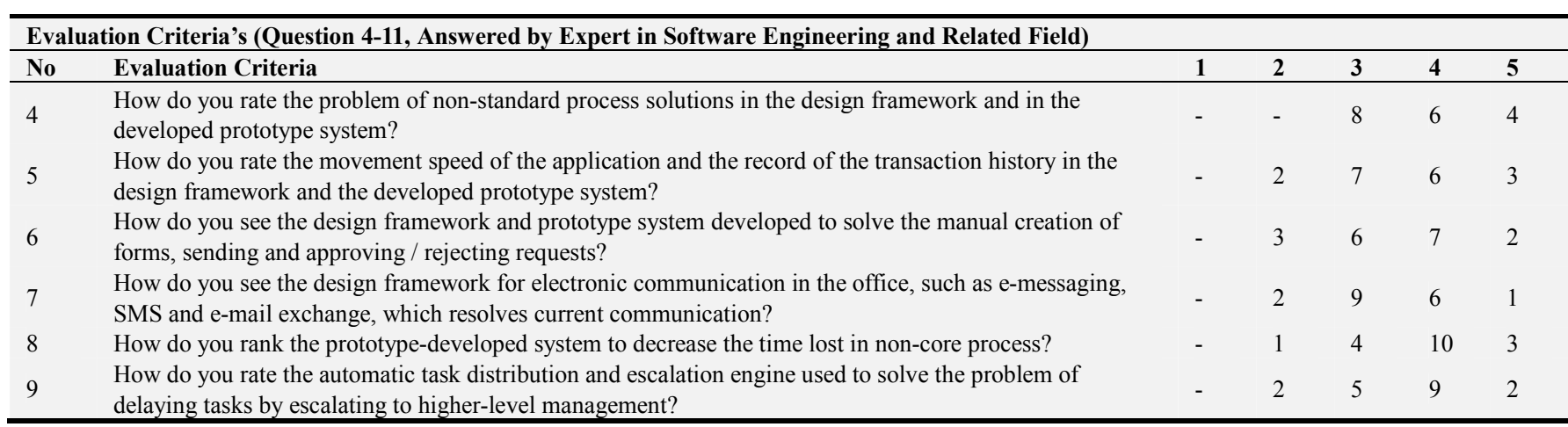

\begin{tabular}{|c|c|c|c|c|}
\hline No & Evaluation Criteria & Yes & No & Yes, in \% \\
\hline 10 & $\begin{array}{l}\text { Do you say the cloud-based design framework and develop the prototype system that has been implemented to create } \\
\text { the smart environment and digital workplace? }\end{array}$ & 15 & 3 & 83.3 \\
\hline 11 & Do you think that this cloud-based electronic office system has improved the institution effectiveness and transparency? & 16 & 2 & 88.8 \\
\hline
\end{tabular}

\subsection{Result and Discussion}

As a user of the Cloud Based Electronic Office Framework (CBEOF) system in Table 3: shows a summary result of the evaluation for developed prototype system.

First criteria, is the satisfaction of the evaluator of the prototype-developed system rated as fair, good, very good, and excellent by $11 \%, 27.7 \%, 38.8 \%$, and $22.2 \%$ of the respondents respectively. As we have seen from the result of the evaluation the developed prototype, most of the evaluator give their satisfaction good and very good. Moreover, most of the evaluator have a good perspective for the prototypedeveloped system.

Second criteria, the rating of the dynamic form builder to design for different forms is good, very good, and excellent by $27.7 \%, 38.8 \%$, and $33.3 \%$ of the respondents respectively. As we have seen from the response most of the respondent responded V. Good and excellent about the dynamic form builder.

Third criteria, the browser response time starting to request a service on the server be rated as fair, good, very good and excellent by $5.5 \%, 50 \%, 33.3 \%$ and $5.5 \%$ of the respondents respectively.

Fourth criteria, the problem of non-standard process solutions in the design framework and developed prototype system rated as good, very good and excellent by $38.8 \%$, $44.4 \%$, and $16.6 \%$ of the respondents respectively.

Fifth criteria, the speed of movement of the request and the record of the transaction history in the design framework and developed prototype system is rated as fair, good, very good and excellent by $11 \%, 27.7 \%, 27.7 \%$, and $33.3 \%$ of the respondents respectively. Moreover, to increase the accountability of the proposed system based on the transaction history for every request, audit data, and raising awareness of customers and users of the system and higher living standards overtime.

Sixth criteria, the design framework and the developed prototype system for solving the manual creation of forms, sending / receiving, and approving / rejecting requests is rated as fair, good, very good and excellent by $16.6 \%, 33.3 \%$, $38.8 \%$, and $11 \%$ of the respondents respectively.

Seventh criteria, the design framework for electronic 
communication in the office, such as E-messaging, SMS and E-mail exchange, which resolves current communication, is fair, good, very good, and excellent by $5.5 \%, 38.8 \%, 44.4 \%$, and $16.6 \%$ of the respondents respectively. Moreover, in order to greater the collaboration by using different communication tools like SMS, E-mail, E-forum discussions among customers, departments, and other administrative officers. There is filing system, central information place, establish consistent, and important decisions. Therefore, there is common understanding how to put new thing, where to find the data, to access anywhere, and regardless of the location.

Eighth criteria, the prototype developed system to decrease the time lost in the non-core process is rated as fair, good, very good and excellent by $5.5 \%, 27.7 \%, 55 \%$, and $16.6 \%$ of the respondents respectively.

Ninth criteria, the automatic task distribution and escalation engine used to solve the problem of delaying tasks by escalating to higher level management is rated as fair, good, very good and excellent by $11 \%, 27.7 \%, 55.5 \%$, and $5.5 \%$ of the respondents respectively.

Tenth criteria, the cloud-based design framework and develop prototype system has been implemented to create the smart environment and digital workplace is rated as Yes, and No by $83.3 \%$, and $16.7 \%$ of the respondents respectively.

Eleventh criteria, the cloud-based electronic office system has improved the institution effectiveness and transparency is rated as Yes, and No by $88.8 \%$, and $10.2 \%$ of the respondents respectively. In addition, the proposed system is transparent because there is standard use of different services form, and process / workflow, the steps where to start and end for given request easily use by customers based on the institutional knowledgebase, and the customers use the services based on their roles.

In general, as we have shown in the previous discussion on the most evaluative response, when the cloud-based electronic office implemented increases effectiveness, transparency of office tasks, decreases the time lost in non-core processes and facilitates the work of the institution, the designer dynamic form for services also responded that it is a good and very good idea to solve the problems of the enormous manual preparation of forms and to have standard forms and workflows in the institution. In addition, the design framework has an automatic distribution of tasks and an escalation engine to complain to a higher level of management and to create a faster work.

\section{Conclusion and Future Work}

\subsection{Conclusion}

Each Ethiopian Higher Education University organizes with academic, research and administrative offices to achieve good learning, to provide researchers and community service. In Ethiopian universities there is problems related to office tasks. Therefore, we have taken EPU to solve related to office tasks. To solve the problems, we propose the cloudbased electronic office framework and prototype implementation for the Ethiopian Public Universities. In this study, we introduced the private cloud platform architecture and prototype implementation of electronic office called CBEOF for sending / processing documents from one office level to another, managing various institutional services, collaboration and messaging, dynamic form creation / generator design, dynamic dispatching of tasks and escalation engines to escalate to higher managerial office if there is any delaying of tasks, to have alerts and notifications, SMS and E-mail exchange, to have forum-discussions and managing institutional knowledgebase. Therefore, this study introduces the concept of implementing cloud computing into office tasks/works to manage and process various institution services to empower the institution employees in their profession and their technological adaptation. CBEOF is based on IBM, NIST Cloud Reference Architecture, and Microsoft Web Application Architecture. We have developed a cloud-based framework of electronic office for EPU. For the designed architecture, a prototype system was developed on the Microsoft Azure platform and deploy on IIS local server.

This NIST architecture focused on electronic office services to increase availability at a low cost and to create a good communication and collaboration network. Various users, ICT professionals, other experts, and colleagues in software engineering and related fields evaluate the developed prototype web application. The proposed framework is just the roadmap for implementing an entire electronic office and service delivery ecosystem. It facilitates and creates a digital workplace solution and an intelligent environment. Designed and synchronized with the needs of modern Ethiopian Universities, it was conceived as an instrument for the next generation Ethiopian University.

\subsection{Future Work}

The proposed system was developed for EPU. The service delivery infrastructures are prepared as management of the university, departments/units, and schools of the institution implemented in the prototype. In addition, employers / users of the institution and different services are created. After that, when identifying the number of attributes of the organization (EPU), design the form builder/generator dynamically for different forms and then distribute them in different departments, teams, and other offices depending on their request. However, the presented architecture and the prototype implemented in this thesis must be improved and evaluated for a more complete and worthy electronic office. Furthermore, even if the integration of this CBEOF system with the signature tool was shown in the proposed framework and architecture, this feature is not implemented in the prototype. When the electronic office implements in higher education institutions, we recommend using community cloud. However, the proposed framework for EPU, we recommend using private cloud.

In addition, there are different components or 
functionalities of e-office not implemented such as: Eforum-discussions and institutional knowledgebase, alerts and notifications to notify clients for different status, implement the preparation of different letter templates and integrate with the signature tool, and design workflow for different business processes, develop electronic messaging and collaboration, escalation and dispatcher engines, SMS and Email exchange.

Here is a list of some of the future work such as:

The proposed framework is developed for EPU and should be implemented in each higher education institution in the future and evaluated with an iterative reflection of employers / users, developers, experts in software engineering and related fields. So that the proposed framework is modified based on feedback and deploy using community cloud deployment.

The study on measuring of performance and effectiveness of the users by having different users.

\section{Abbreviations}

NIST National Institute of Standards and Technology

CBEOF Cloud Base Electronic Office Framework

EPUs Ethiopian Public Universities

SMS Short Message Service

IIS Internet Information Service

ICT Information Communication Technology

IT Information Technology

IBM International Business Machine Cloud

CCRAs Computing Reference Architectures

\section{Data Availability}

The data used to support the findings of this study are available from the corresponding author upon request.

\section{Conflicts of Interest}

The authors declare no conflicts of interest regarding the publication of this paper.

\section{References}

[1] R. Kumar, M. K. Sharma, et al, "Impact of ICT in Growth and Development of rural System in Uttarakhand," World Rural Observations, 2011.
[2] Lallana, Emmanuel C., "mGovernment: Mobile/Wireless Applications in Government," [Online]. Available: http://www.egov4dev.org/mgovernment/. [Accessed 09 March 2017].

[3] Case Study on implementation of eOffice in Mantralaya, Mumbai, Government of Maharashtra, 2013-2014.

[4] Rastogi, Dr. Ashish, "A Model based Approach to Implement Cloud Computing in E-Governance," vol. Volume 9- No. 7, pp. Page 1-4, November 2010.

[5] G. Sahoo, K. Mukherjee, "Cloud Computing: Future Framework for e-Governance," vol. Volume 7- No. 7, pp. Page 1-4, October 2010.

[6] Mohammed, Endris, "Participatory Indigenous Knowledge Management Architecture for Traditional Medicine," Adama Science and Technology University, 2016.

[7] Kothari, C. R., "Research methodology: methods and techniques," New Age International, 2008.

[8] NJ, Hoboken, "Introduction to qualitative research methods 3rd ed," US: John Wiley \& Sons Inc, vol. 34, no. 6, pp. 68770, 1998.

[9] Uma D and Pansiri, J. ogulu, "Mixed methods: A research design for management doctoral dissertations," Management research review, vol. 34, no. 6, pp. 687-70, 2011.

[10] Fallman, Daniel, "Why Research-oriented Design Isn't Design oriented research," Knowledge, Technology \& Policy, vol. 20, no. 3, pp. 193-200, January 2007.

[11] etal, Hevner A., "Design Science in Information Systems Research," MIS Quarterly, vol. 28, no. 1, pp. 75-105, 2004.

[12] "Stratified sampling calculator," [Online]. Available: $\mathrm{http}: / /$ stratifiedsampling.orgfree.com/calc.php.

[13] IBM Cloud Computing Reference Architecture (CCRA) 4.0 Overview, IBM, 2014.

[14] "NIST cloud reference architecture".

[15] Microsoft Corporation, "Web Application Architecture Guide," Microsoft Corporation, 2008. [Online].

[16] Mattsson, M. et al (n. d), "Software Architecture Evaluation Methods for Performance, Maintainability, Testability, and Portability."

[17] Keith G. Diem, Ph. D., "A Step-by-Step Guide to Developing Effective Questionnaires and Survey Procedures for Program Evaluation \& Research," Rutgers Cooperative Extension Program. 